\title{
Editorial
}

\section{Estudios de la India: Un monográfico*}

\author{
Julio César Ossa \\ Universidad de San Buenaventura (Colombia) \\ Gabriel Martino \\ Universidad de Buenos Aires; Conicet (Argentina)
}

Referencia formato APA: Ossa, J. \& Martino, G. (Ed). (2016). Estudios de la India: Un monográfico. Rev. Guillermo de Ockham, 14(1), 7-10.

doi: http://dx.doi.org/10.21500/22563202.2403

La publicación en América Latina de un número monográfico sobre estudios de la India es un fenómeno académico con una significación sociológica y política muy interesante. Es evidencia del encuentro entre dos regiones periféricas respecto de los centros científicos y académicos mainstream más prestigiosos de Europa y de Norteamérica. Es cierto que si bien tal encuentro procura la producción y promoción propia (y colaborativa) de conocimiento, no carece de signos de dependencia académica respecto de los mencionados centros. Un relevamiento de la bibliografía utilizada por los especialistas que participan de nuestro número puede brindarnos una noción del grado de tal dependencia. No obstante, este encuentro también es un claro índice de la voluntad y de la capacidad de nuestras regiones para el establecimiento de vínculos académicos bilaterales.

Si bien las agendas y las metodologias características de los circuitos académicos centrales ejercen una profunda influencia sobre esta clase de trabajos, creemos que instancias como el presente número monográfico pueden dar lugar a nuevas maneras de encarar las investigaciones mediante la definición de objetivos, estándares, metodologías y representaciones definidas por las necesidades y las perspectivas propias de los centros involucrados en el diálogo.

Cabe señalar, asimismo, que nuestra labor no es en absoluto pionera. Tal como la doctora Flora Botton afirmó en una de sus contribuciones en el último Congreso Internacional de Aladaa, "un congreso de estudios de Asia en América Latina es consecuencia del trabajo de pioneros como Fernando Tola."
Quizás vale la pena hacer un alto en esta editorial y presentar a nuestros lectores un breve panorama de la producción académica de los estudios de la India a nivel mundial. El objetivo de este preámbulo es ofrecer un paisaje, en perspectiva bibliométrica, del alcance académico y conceptual de este monográfico.

Empecemos, entonces, por decir que consultamos la base de indexación Scopus utilizando los siguientes criterios de búsqueda: Indian Studies, Indian Philosophy, Estudios de la India y Filosofía de la India. Además, se incluye en la búsqueda diferentes tradiciones, doctrinas y formas literarias tales como Nyāya, Vaiśeșika, Sāṃkhya, Yoga, Mīmāṃsā, Vedānta, Āgama, Tantra, Sūtra, Stotra, Advaita, Darshana y Darśana.

La búsqueda arroja un total de 1581 publicaciones académicas. La mayor producción académica se encuentra condensada en artículos (51\%), libros (23\%) y capítulos de libro (13\%). Los países que más producción tienen son Estados Unidos (35 \%), India 10 \% y Reino Unido (10\%). Por su parte los países latinoamericanos tienen una cuota de participación muy modesta (4\%); entre ellos se encuentran México (once artículos), Brasil (siete artículos), Argentina (cinco artículos) y Chile (cuatro artículos).

Respecto a la trayectoria histórica de la producción académica de los estudios de la India puede decirse que desde el año 1958 hay registros de artículos publicados en Scopus. Desde entonces y hasta el año 2008 la producción académica evidencia un número discreto de publicaciones, alrededor de diez artículos por año. A partir del 2009

* Por primera vez la Revista Guillermo de Ockham presenta un número monográfico dedicado a los estudios de la india en las ciencias sociales, el arte y las humanidades. Este monográfico fue posible gracias a la valiosa contribución de Gabriel Martino Ph.D, quien cumplió con las funciones de un editor invitado. Para la revista es un honor contar con el apoyo y colaboración del doctor Martino quien nos acompańa en el Comité Editorial desde el año 2014

1. Véase la semblanza Fernando Tola incluida en el presente número. 
se empieza a evidenciar un incremento sustantivo en la producción académica.

Un análisis de autoría nos muestra los autores más representativos de la producción académica de los estudios de la India (Figura 1).

En la Figura 1 se destacan tres clústeres (rojo, verde, violeta). En el clúster rojo se encuentran los autores con mayor producción indexada en Scopus (ellos son Bhushan y Garfield). En el clúster verde se encuentran los autores más representativos en el desarrollo de investigación en la filosofía de la India en Latinoamérica, entre ellos Fernando Tola y Carmen Dragonetti. ${ }^{2}$ Cabe mencionar el trabajo de autores de importante trayectoria investigativa en el campo y con producción académica de alto impacto que forman parte de este monográfico a saber: Ramkrishna Bhattacharya, Johannes Bronkhorst, Claus Oetke e Ivan Andrijanić.

La Figura 2 muestra el mapa semántico de relaciones entre los conceptos de mayor incidencia de la producción académica dedicada a los estudios de la India. Por otro lado, encontramos que los conceptos más abordados son Buddhism, Sanskrit, Advaita, Brahman, Darhmaktri, Soul y Advaita Vedanta.

Vale la pena decir que estos conceptos fueron el núcleo de discusión y reflexión en varios artículos de este monográfico. Estos debates abordan aspectos clásicos pertenecientes a los seis sistemas de la filosofía India. Se empieza por un abordaje ontológico que abre el debate sobre la naturaleza del término darśana y su intrínseca relación con la filosofía y la religión de la India moderna. Así mismo, pasamos por un arqueo histórico de los Cārvākas, quienes representan la escuela de pensamiento filosófico corte materialista más antigua de la India y, en su artículo, Bronkhorst ofrece una clara discusión acerca de diferentes elementos que podemos considerar característicos de esta vertiente. ${ }^{3}$ La Figura 3 presenta la red de conocimiento que se teje al interior de los abordajes académicos dedicados a los estudios de la India en este monográfico.

En esta red de conocimiento encontramos un acercamiento hacia una cultura por el conocimiento del sánscrito que nos permite conocer aspectos concernientes

Figura 1

Mapa de coautoría de los autores más representativos de la producción académica de los estudios de la India

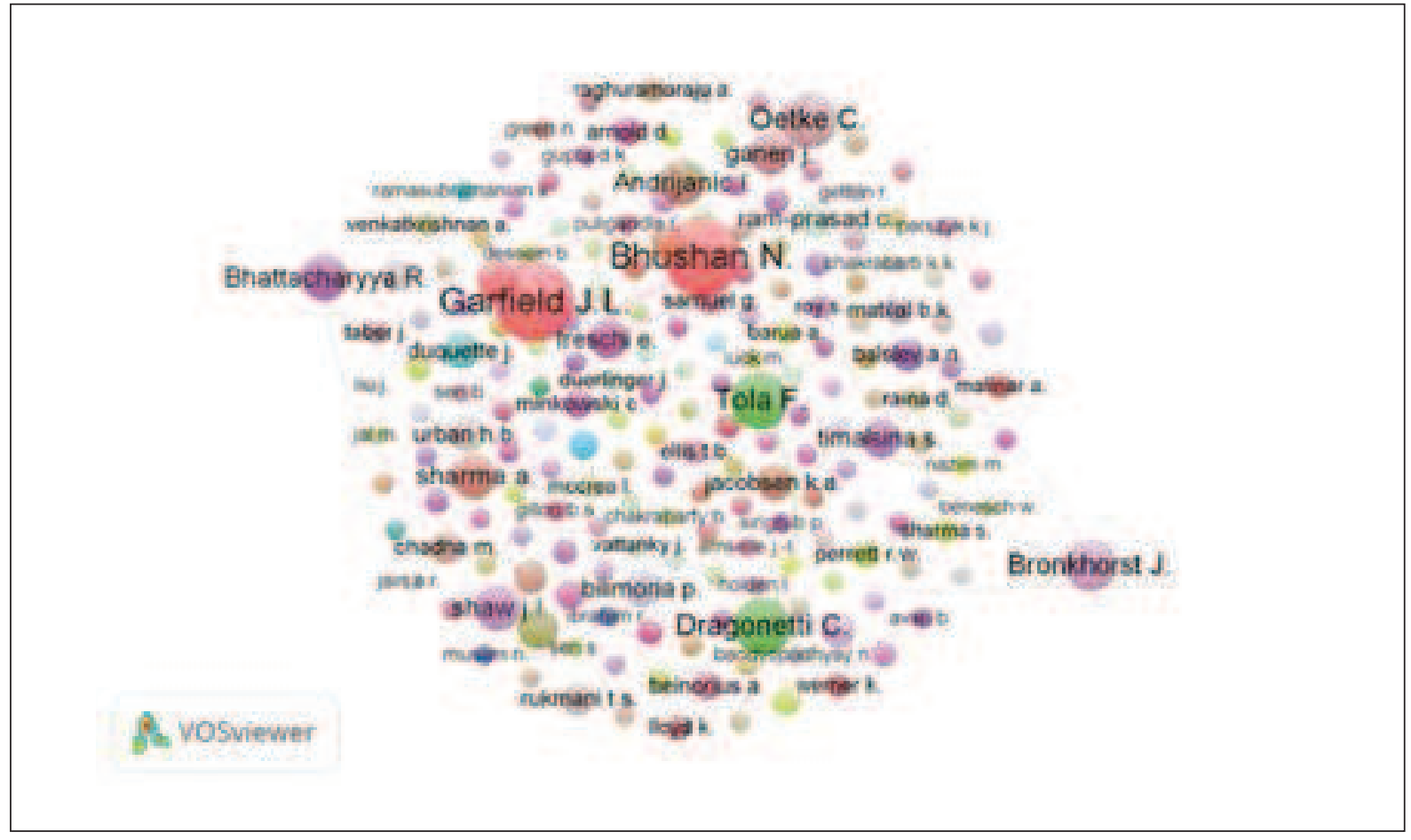

2. Véase Tripathi (2012), quien realiza una reseña de los estudios sánscritos fuera de India en el período 1950-2010. De Latinoamérica el autor solo menciona a la Argentina y de este país, solo a los especialistas F. Tola y C. Dragonetti.

3. Véase el artículo del profesor Johannes Bronkhorst incluido en este número. 
Figura 2

Mapa semántico de las palabras con mayor número de coocurrencias

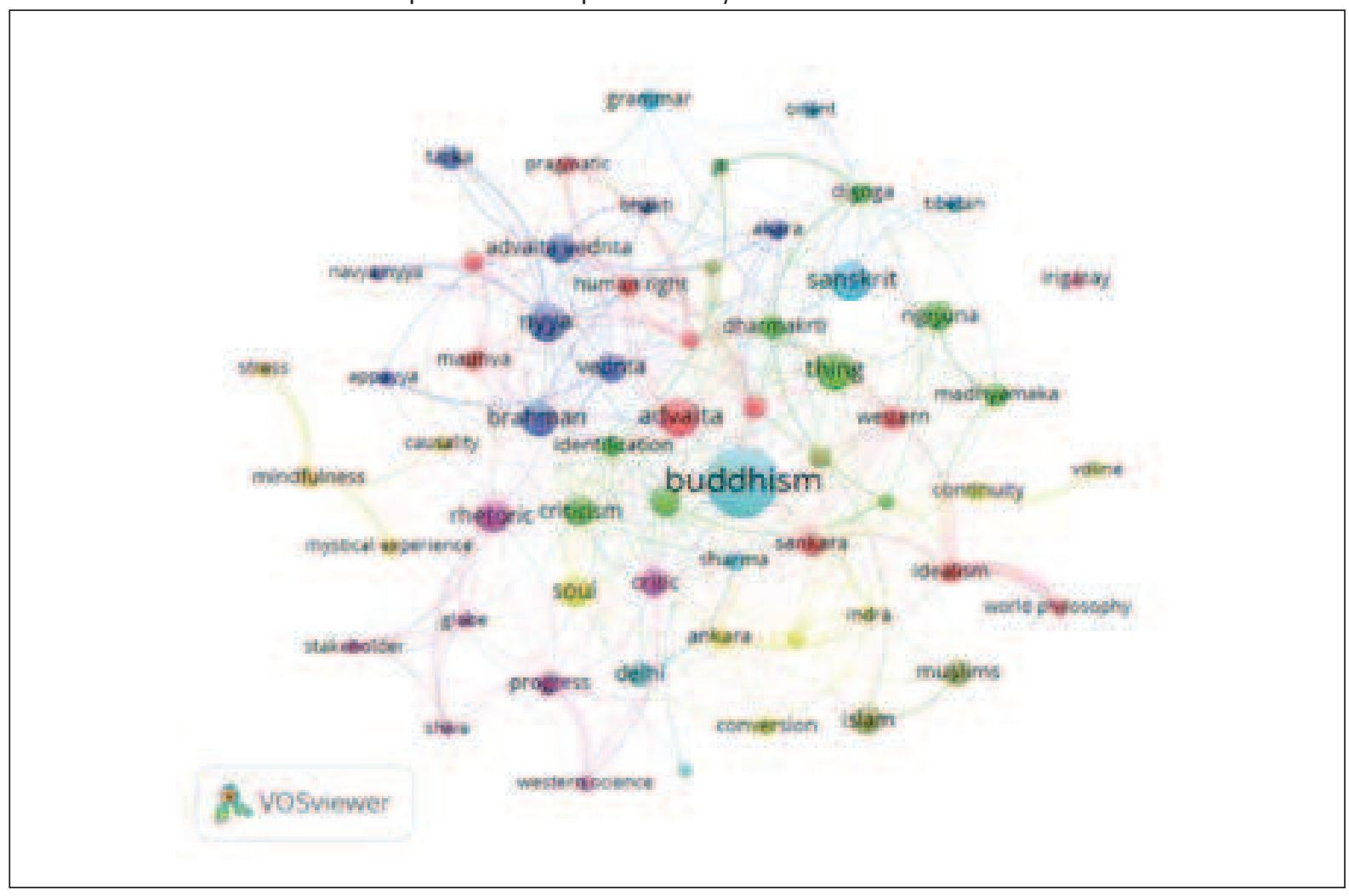

Figura 3

Red de conocimientos que se abordan en el monográfico

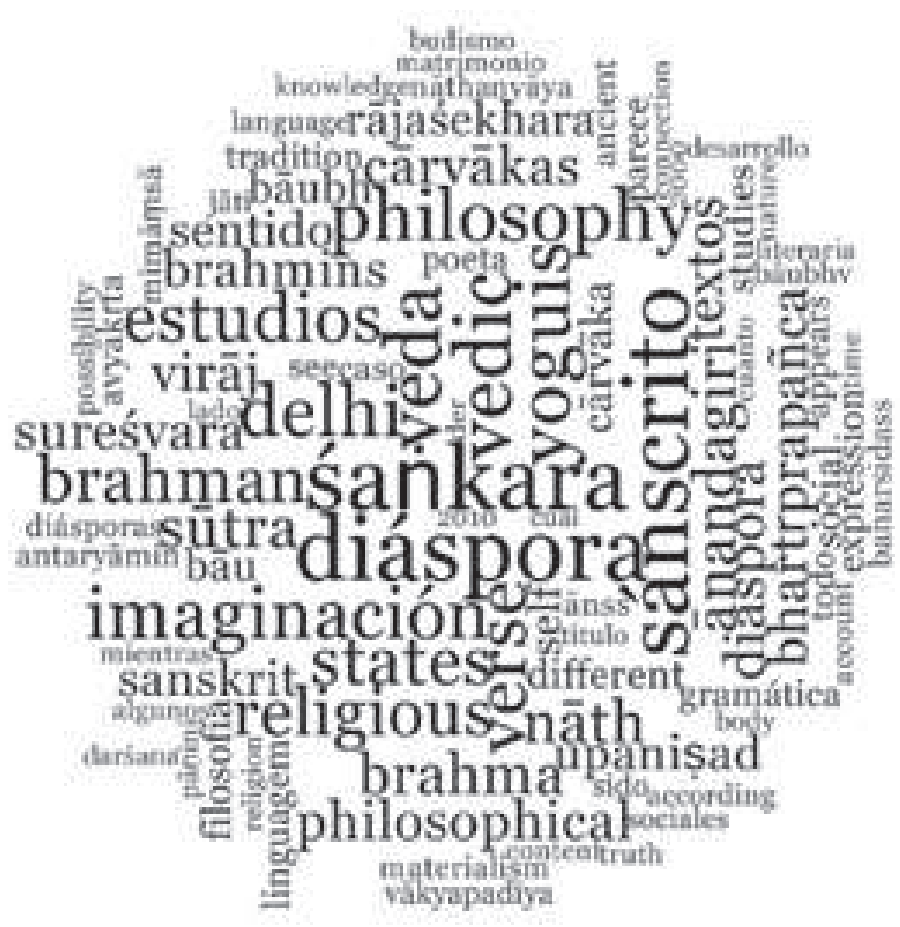


a los estudios de la India y su relación con el orden de lo social, a saber: la evolución de los estados de Brahaman, la configuración de la identidad Nath, el acontecimiento de las diásporas indias y el fenómeno de las viudas en la India, los cuales forman parte de esta red de conocimientos específicamente abordados por indiólogos para toda la comunidad académica. Esperamos que nuestros lectores disfruten la lectura tanto como nosotros disfrutamos la edición de este número. 